\title{
TWO-BODY ABRASIVE WEAR BEHAVIOUR OF IN-SITU Al-TiC PARTICLE COMPOSITES: INFLUENCE OF TiC REINFORCEMENT AND CONTENT IN THE ALLOY MATRIX AND EXPERIMENTAL PARAMETERS
}

\author{
B.K. Prasad, S. Rathod, O.P. Modi, G.K. Gupta, M.S. Yadav \\ CSIR-Advanced Materials and Processes Research Institute, Bhopal-462026, India
}

\begin{abstract}
This study pertains to observations made on the abrasive wear response of Al-TiC composites under varying applied load and traversal distance conditions. The influence of $\mathrm{TiC}$ particle reinforcement and its content in the matrix on the abrasion characteristics of the samples was investigated. The composites were prepared by generating the reinforcement phase (TiC particles) from within the matrix employing a hybrid in-situ technique consisting of a combination of steps involved in powder and liquid metallurgy routes of synthesizing metal matrix composites. The unreinforced matrix alloy (AA2014) was also tested under identical experimental conditions for comparison purposes. Properties characterized were wear rate, frictional heating and friction coefficient. Microstructural features of the samples and characteristics of wear surfaces, subsurface regions and abrasive medium have also been examined.
\end{abstract}

The TiC reinforcement led to improved abrasion resistance (inverse of wear rate), the degree of improvement increasing further with the rising concentration of the TiC particles in the alloy matrix. Increasing applied load led to deterioration in the wear behaviour of the samples while a reverse trend was followed as the traversal distance was raised. The severity of frictional heating was noted to increase with load. On the contrary, friction coefficient tended to decrease with increasing load except for the composite containing the highest concentration of $\mathrm{TiC}$ wherein a reverse trend was noticed. Both frictional heating and friction coefficient increased sharply with traversal distance initially. This was followed by a reduction in the rate of temperature increase at longer traversal distances whereas friction coefficient was observed to attain steady state condition after showing a decrease in some cases. The presence of $\mathrm{TiC}$ reinforcement in the alloy matrix and its increasing content led to a decrease in the friction coefficient and the severity of frictional heating. The observed wear behaviour has been substantiated through the characteristics of abraded surfaces and subsurface regions of the samples and degradation of the abrasive medium. Operating material removal mechanisms have also been examined.

Keywords: Al-TiC in-situ composites, high-stress abrasion, wear behaviour, material removal mechanisms

*Corresponding author: B.K. Prasad (braj.kprasad@gmail.com)

\section{INTRODUCTION}

Al alloy metal matrix composites (MMCs) are widely used in a variety of tribological and other engineering applications including automobile, aircraft, space equipment and structural components [1-10]. Mining and mineral handling/ processing equipment could be other potential areas of applications for the MMCs [6]. It has been observed that wear of critical components like brake drums, cylinder blocks, cylinder liners, drive shafts etc. greatly affect the overall operational efficiency in automotive applications. Automobile companies like Honda, Nissan, Toyota, and General Motors etc. have successfully 
implemented these Al-MMCs in different engine applications by using various particle and fiber type reinforcements such as $\mathrm{SiC}$, $\mathrm{Al}_{2} \mathrm{O}_{3}$, graphite etc. [5]. Superior physical, mechanical and tribological properties of Albased MMCs reinforced with TiC particles have made them particularly attractive for aerospace, automotive, defense, and structural applications $[1,4]$. Al-Cu alloys are known for their good strength properties and thus have great potential for a wide range of the mentioned applications $[1,4]$. However, this requires imparting elevated temperature strength and wear (including abrasion) resistance to the alloy system to suit the applications [1,2]. This could effectively be done through the development of Al-Cu alloy MMCs containing reinforcement of ceramic dispersoid phases like $\mathrm{TiC}, \mathrm{SiC}, \mathrm{Al}_{2} \mathrm{O}_{3}, \mathrm{TiB}_{2}$, $\mathrm{B}_{4} \mathrm{C}, \mathrm{ZrB}_{2}$ etc. that can impart high specific strength, stiffness, modulus, thermal stability and wear resistance to the material system [3,11-17].

It has been observed that factors like size, shape, content and mode of distribution of the dispersoid phase in the matrix greatly control the response of composites [18-21]. Added to them is the nature of the dispersoid/matrix interfacial bonding. For example, fine, spherical and uniformly distributed dispersoid phase along with sound particle/matrix bonding improves the properties of composites. Moreover, the reinforcement content becomes more effective in controlling the properties if the dispersoid/matrix interfacial bonding is sound [19,20,22]. Control of parameters like the dispersoid size, content, mode of its distribution in the matrix and nature of dispersoid/matrix interfacial bonding has rather been treated as a challenge towards the synthesis of good performing composite materials. It may be mentioned that the process of generating and/or adding the dispersoid phases plays a major role in controlling their size, shape, content and mode of distribution in the matrix.
Al alloy particle composites are conventionally prepared either by powder metallurgy route or liquid metallurgy technique involving ex-situ (external) addition of the dispersoid phase directly to the matrix [14,23-25]. It has been suggested that the mode of distribution of the dispersoid particles in the matrix could more effectively be controlled by adopting the powder metallurgy route but there is a wide scope for the material to contain high porosity. The liquid metallurgy route including the one involving the stir casting technique has been viewed as the most economically viable, practical and attractive process for making composites [23,26-30]. However, there are some inherent limitations even with this process like segregation of the dispersoid phase in the matrix, inferior (dispersoid/ matrix) interfacial bonding leading to interfacial porosity/defects, segregation of the dispersoid phase etc. bringing about poor properties of the composites [26,31-33]. The problem becomes more acute while adding fine dispersoid particles in view of increased tendency of the particles towards coagulation. Poor wettability characteristic of the dispersoid particles with the (molten) matrix is basically responsible for the mentioned problems [26,31-33]. This problem could partially be resolved through the pretreatment of the dispersoid particles before adding them to the melt $[11,26]$. In-situ generation of the reinforcement particles from within the matrix has been observed to be beneficial in terms of its ability to produce sound dispersoid/matrix interfacial bonding and reinforce very fine (dispersoid) particles with their fairly uniform distribution in the matrix [34-44]. The highly exothermic nature of the in-situ reaction makes it self-sustaining type and finishes fast thereby leading to the generation and homogeneous distribution of thermally stable fine dispersoid particles in the matrix [36]. The beneficial effects result from clean dispersoid/matrix interface bringing about excellent wettability $[27,35,45-50]$. 
Al matrix particle in-situ composites could be synthesized employing self-propagating high temperature synthesis (SHS) [40], powder metallurgy [41], infiltration [42] and casting $[43,44]$. Amongst different liquid metallurgy processes for synthesizing in-situ composites, flux assisted casting technique has been reported to be an effective method bringing about good dispersoid/matrix bonding in view of improved wettability characteristics and hence superior mechanical properties compared to the ones processed using powder metallurgy route $[11,43]$. However, there lies the danger of partial retention of the flux by the composite melt thus causing contamination in this case. TiC particulates have been generated in-situ in $\mathrm{Al}$ alloy melts by injecting $\mathrm{CH}_{4}$ gas in the Al-Ti melt [38]. However, the process of using a carbonaceous gas has some practical difficulties such as the requirement of complicated apparatus and a problem of controlling the volume fraction of the $\mathrm{TiC}$ particles generated in the composites [39].

In-situ composites are an emerging group of materials with distinct advantages over the conventionally prepared ones [27,34-37,4551]. They are also exclusively being studied due to their potentially low fabrication cost [39]. Several types of ceramic particles have been reinforced in $\mathrm{Al}$ alloy matrices by the insitu technique. They include $\mathrm{SiC}[52], \mathrm{TiB}_{2}$ [15], $\mathrm{B}_{4} \mathrm{C}$ [16], $\mathrm{ZrB}_{2}$ [17], TiC [12,34] etc. Some information is available pertaining to the influence of the varying dispersoid/matrix interfacial characteristics on the properties of composites synthesized using different processing techniques [11,53], types of reinforcement [43], chemical composition of the matrix [54], heat treatment $[55,56]$ etc.

TiC exhibits high hardness and its addition improves thermal stability and elevated temperature properties of $\mathrm{Al}$ [27]. TiC reinforcement to $\mathrm{Al}$ alloys has been of special research interest nowadays in view of its specific features like better wettability with $\mathrm{Al}$, lower density, superior thermal stability, low chemical reactivity, high specific strength, high hardness, high elastic modulus, high creep resistance, better stiffness and superior wear resistance compared to other commonly used carbide reinforcements $[1,2,14,27,28,39,53,57-60]$. It may also be mentioned that $\mathrm{TiC}$ does not affect electrical properties of composites as adversely as other reinforcements. Al-TiC particle composites are treated as the new generation composites in view of their superior physical and mechanical properties such as high hardness, high melting point, high elastic modulus and good thermal and electrical conductivity $[2,14]$. They have drawn scientific attention for aerospace, automotive, structural and defence applications [1,4,57,61-64]. The composites could also be used as grain refiners in $\mathrm{Al}$ melt [5,37,50,65-68].

Wear behaviour of materials is controlled by a number of material and experimental parameters. Material related factors include hardness, strength, microstructural features, chemical composition etc. [18-20,27,33,34,6980]. In the case of composites, additional factors controlling the wear behaviour are morphology, mode of distribution and content of dispersoid phase and the nature of dispersoid/matrix bonding $[2,6,19,20,22,27,28,34,39,45,70,71,76,79,81-$ 90]. Experimental parameters include applied load, traversal distance, speed etc. $[2,27,28,39,45,74,76,77,80,82,87,89,90]$. As far as abrasion is concerned, the size and hardness of the abrasive particles also come into picture in controlling the wear response $[36,74,87,91,92]$. Studies suggest that the above mentioned (material and experimental) parameters control the wear behaviour of materials in a complex manner and produce even a synergistic effect in this regard $[74,76]$. In other words, any of the parameters may not necessarily produce same/similar effects in all cases and that the degree of effectiveness of one parameter may also be affected 
(accelerated/decelerated) significantly by the presence of any other of the factors in place while the joint influence of two parameters may not be the simple summation of their individual effects. The effect of $\mathrm{TiC}$ particle content and size on the microstructure and properties of Al-TiC composites synthesized by powder metallurgy and flux assisted liquid metallurgy processes has been studied [2,39]. The studies suggest improved hardness and superior wear resistance with increasing TiC content while particle size produced a reverse influence on the wear response [2,39].

An appraisal of the above, suggests that there is a need to develop a more effective technique of preparing composites. In this context, development of a hybrid process consisting of a blend of typical steps involved in the case of powder metallurgy and liquid metallurgy processes is envisaged to prove beneficial in terms of improved soundness of the composite and better homogeneity of distribution of the fine dispersoid particles in the matrix. Also, there exist several studies pertaining to the influence of various parameters on the wear response of Al MMCs. However, most of them have focused on the sliding wear behaviour $[1,2,6,17-22,33,61,81,85]$ and abrasive wear characteristics $[6,69-77,82-84,86-88,91,92]$ of $\mathrm{Al}$ alloys and ex-situ synthesized Al MMCs while very limited information is available dealing with the assessment of the abrasive wear response of $\mathrm{Al}$ alloy in-situ composites containing fine reinforcement of TiC particles despite a wide scope of work $[28,45]$.

In view of the above, an attempt has been made in this study to synthesize Al composites with 5 and $10 \%$ fine $\mathrm{TiC}$ particle reinforcement employing a hybrid in-situ technique and investigate their abrasive wear characteristics at different applied loads and traversal distances. Characterization of microstructural features of the samples prior to testing and microscopic examination of abraded surfaces, subsurface regions and abrasive medium (before and after testing the samples) was also carried out to understand the role of different material and experimental parameters in controlling the wear response of the material system.

\section{EXPERIMENTAL PROCEDURES}

\section{Material Synthesis and Sample Preparation}

Material synthesis in this study included three steps namely (a) preparation of pellets of powder mixture, (b) incorporating the pellets in the alloy melt to form TiC particles in-situ therein and (c) pouring the composite melt in the mould to make castings. Pellet preparation involved mixing the powders of $\mathrm{Ti}$ and $\mathrm{C}$ in equal proportions along with that of $\mathrm{Al}$ using a planetary ball mill (ball/powder ratio $\sim 2$ ) and pressing the powder mix inside a mould (40 $\mathrm{mm}$ diameter) at $25 \mathrm{MPa}$ pressure at ambient temperature. The alloy melt was prepared by melting the constituent elements in required quantities so as to arrive at the desired chemical composition of the matrix alloy conforming to Al alloy 2014 (Table 1). Attempts were made to add the low melting elements towards the end of the melting operation to avoid/minimize their losses due to evaporation. This was followed by the gradual addition of the pellets to the alloy melt to be able to in-situ generate 5 and $10 \mathrm{wt} \% \mathrm{TiC}$ particles in the alloy matrix. The alloy melt was stirred simultaneously with the help of a stirring mechanism while adding pellets to the melt. The composite melt was poured in a metallic mould to solidify it in the form of 12 $\mathrm{mm}$ diameter and $120 \mathrm{~mm}$ long cylindrical castings.

Samples for abrasion testing, hardness and density measurement and microstructural examination were prepared by machining the castings. The samples for abrasion testing were in the form of $8 \mathrm{~mm}$ diameter and $30 \mathrm{~mm}$ long cylindrical pins with a fine hole near their flat 
ends. For hardness and density measurements, $12 \mathrm{~mm}$ diameter and $15 \mathrm{~mm}$ thick samples were prepared. The samples were polished well before conducting the tests/measurement. The specimens for microstructural examination were prepared in a manner similar to those for hardness and density measurement and etched with Keller's reagent.

\section{Measurement of Hardness and Density}

Hardness of the samples was measured using a Vickers hardness tester at an applied load of 30 $\mathrm{Kg}$ while density was determined employing water displacement technique. A Mettler microbalance with a precision level of $10^{-5} \mathrm{~g}$ was used for weighing the samples in water and air. An average of five observations has been considered in this study.

\section{$\underline{\text { Abrasion Tests }}$}

Two-body abrasion tests were carried out on the (pin) samples. The apparatus used for conducting the abrasive wear tests was a DUCOM (Bengaluru, India) make pin-on-disc (TR-20LE) machine with the disc covered with the abrasive medium. The abrasive medium consisted of $15 \mu \mathrm{m} \mathrm{SiC} \mathrm{particles} \mathrm{firmly}$ adhering on to a strong paper base. The abrasive paper base was pasted firmly with the disc to prepare the (abrasive) counterface. Figure 1 shows the morphology of the abrasive particles fixed on the paper base. A magnified view of the pin-on-disc test system/apparatus is shown in Fig. 2. This test methodology/ configuration gives rise to a situation wherein the abrasive particles are firmly held in position against the specimen surface under the applied load and do not enjoy the freedom to move/roll freely in between the contacting surface or bounce back into the counterface. Under the circumstances, the abrasive particles get highly stressed against the specimen surface since the total applied load/stress is transferred on to the specimen surface giving rise to high-stress loading conditions.

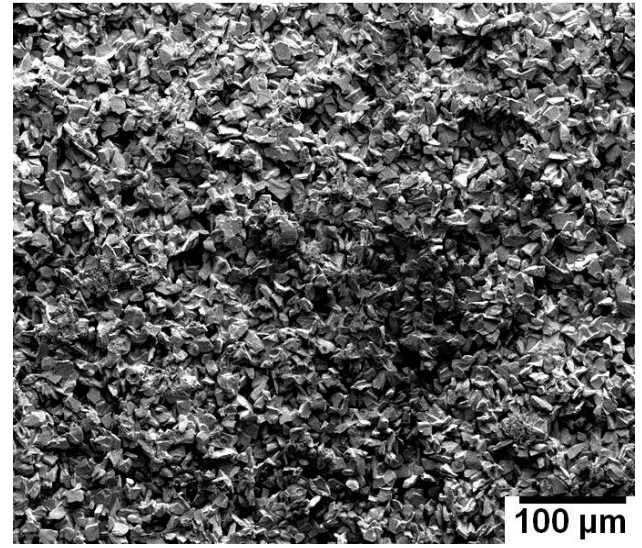

(a)

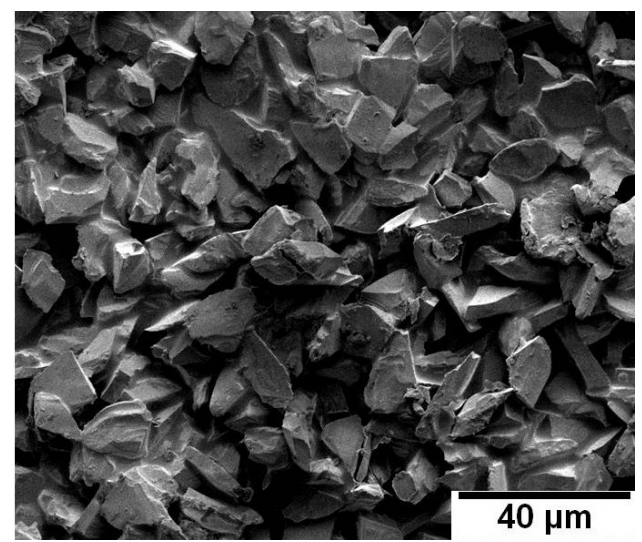

(b)

Fig. 1 Fresh abrasive medium revealing the features/ morphology of SiC particles fixed on the paper base prior to abrasion testing

Accordingly, these tests are termed two-body (high-stress) abrasion tests. All the tests were conducted at the applied loads of 5 and $20 \mathrm{~N}$ at a fixed traversal speed of $1 \mathrm{~m} / \mathrm{s}$ while traversal distance was varied in the range of 100-500 m. Load on the samples was applied with the help of a cantilever mechanism. Wear rate was determined by weight loss measurement technique. The samples were cleaned well and weighed prior to and after conducting the abrasion tests. Weighing was done using a Mettler microbalance with a precision level of $10^{-5} \mathrm{~g}$. Further, temperature rise was monitored during the tests through a chromel-alumel thermocouple inserted in the hole made near the contacting surfaces of the specimens. Moreover, friction force was also measured in 


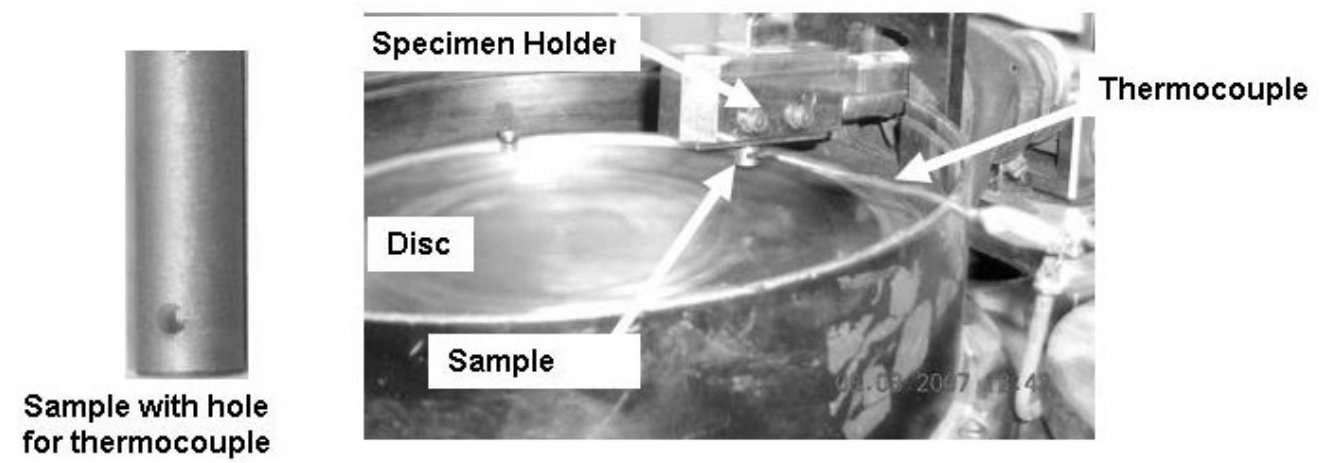

Fig. 2 Photographic representation of the wear test apparatus and specimen

this study using a force transducer and then converted into friction coefficient.

The methodology adopted during abrasion testing involved fixing the abrasive medium on to the disc surface and the sample in the specimen holder. This was followed by loading the sample to the desired extent against the abrasive medium, allowing the sample to travel the fixed traversal distance, removing and cleaning the sample and measuring its weight loss.

\section{$\underline{\text { Microscopy }}$}

Microstructural features of the samples were determined using computerized optical and scanning electron microscopes attached with a digital photographic and recording system. The SEM used was JEOL, Japan Make (JSM5600) and SE detector was employed for the microscopic investigations. The polished and etched samples were sputtered with gold prior to their SEM examination.

Wear surfaces and subsurface regions of the tested samples and the abrasive medium were examined using a scanning electron microscope (SEM). The samples for the wear surface examination were cleaned well, mounted on brass studs and sputtered with gold for their examination. In order to characterize subsurface regions, transverse sections in the direction of sliding were cut from the tested samples, mounted in polyester resin, polished according to standard metallographic techniques, etched with Keller's reagent and sputtered with gold. The abrasive medium prior to and after conducting the abrasion tests was also mounted on brass studs with the help of a double sided tape and sputtered with gold to study the change in its features as a result of abrading the samples.

\section{RESULTS}

\section{Microstructure, Hardness and Density}

Figure 3 shows microstructural features of the matrix alloy and composites. The matrix alloy revealed dendritic structure (Fig. 3a) consisting of primary $\alpha$ dendrites surrounded by the $\mathrm{Al}(\alpha)-\mathrm{CuAl}_{2}$ eutectic and iron rich phase in the form of Chinese script (Fig. 3b, regions marked by $\mathrm{A}$, arrow and $\mathrm{B}$ respectively). A detailed discussion about the Chinese script Fe-rich phase is available elsewhere [93,94]. The matrix structure of the composites remained practically unchanged due to $\mathrm{TiC}$ addition (Fig. 3c). The presence of $\mathrm{TiC}$ particles in the alloy matrix may be seen clearly in the case of the composites (Fig. 3d\&e). The TiC particles were observed to be in the size range of submicron to $\sim 4 \mu \mathrm{m}$ with sound particle/matrix interfacial bonding (Fig. 3e, region marked by $\mathrm{C}$ ).

Table 1 shows the density and hardness of the samples. The presence of $\mathrm{TiC}$ particles led to slightly increased density and limited 


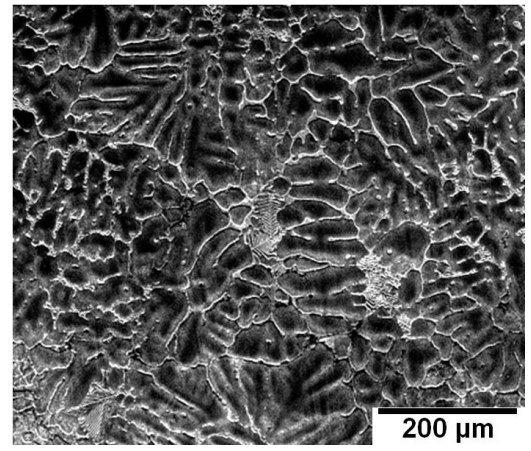

(a)

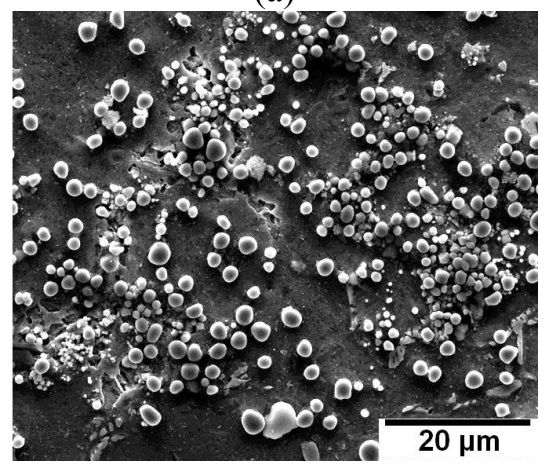

(d)

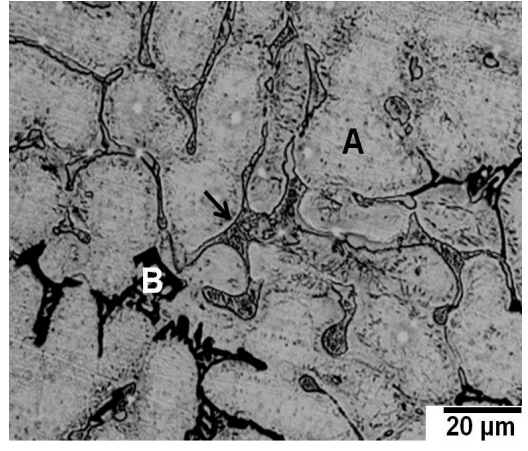

(b)

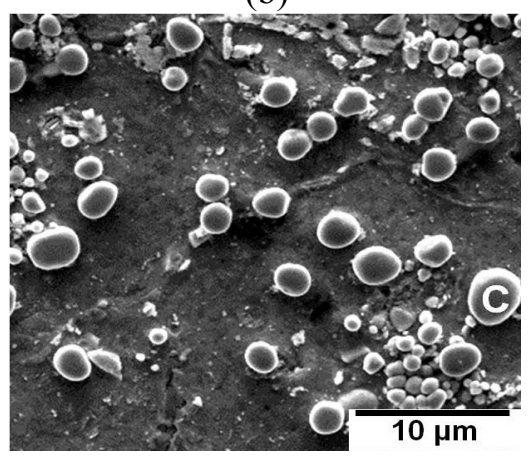

(e)

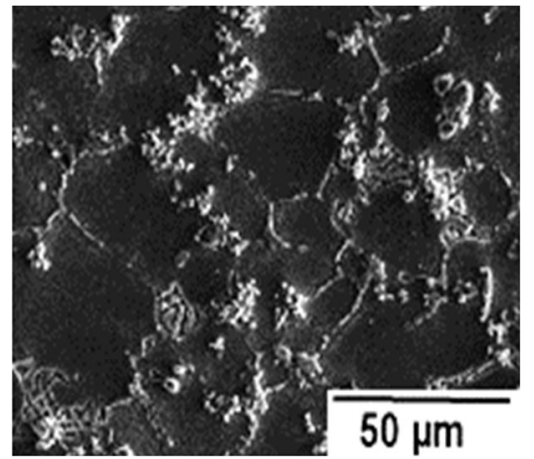

(c)

Fig. 3 Microstructural features of the $(a \& b)$ matrix alloy and (c-e) composites containing (c) 5\%TiC and (d\&e) 10\% TiC particles [A: primary $\alpha$, arrow: Al-Cu eutectic, B: Chinese script phase and C: TiC

Table 1 Chemical composition (wt\%), hardness and density of the AA 2014 matrix alloy and composites

\begin{tabular}{|c|c|c|c|c|c|c|c|}
\hline \multirow{2}{*}{ Material } & \multicolumn{5}{|c|}{ Composition, wt \% } & \multirow{2}{*}{$\begin{array}{c}\text { Hardness, } \\
\text { HV }\end{array}$} & \multirow{2}{*}{$\begin{array}{l}\text { Density, } \\
\text { g.cm }{ }^{-3}\end{array}$} \\
\hline & $\mathrm{Al}$ & $\mathrm{Cu}$ & $\mathrm{Mg}$ & $\mathrm{Si}$ & $\mathrm{TiC}$ & & \\
\hline Matrix alloy & $*$ & 4.56 & 0.75 & 0.86 & 0 & 85 & 2.80 \\
\hline \multirow{2}{*}{ Composites } & & \multirow{2}{*}{\multicolumn{2}{|c|}{ Matrix alloy }} & & 5 & 90 & 2.88 \\
\hline & & & & & 10 & 92 & 2.90 \\
\hline
\end{tabular}

*: remainder

improvement in hardness. An identical trend was also observed with the increasing concentration of $\mathrm{TiC}$ in the alloy matrix.

\section{$\underline{\text { Wear Behaviour }}$}

Figure 4 shows the wear rate of the samples plotted as a function of traversal distance. The influence of $\mathrm{TiC}$ reinforcement and applied load on the wear response of the matrix alloy is also evident from the figure. The wear rate decreased with increasing traversal distance. Also, the rate of reduction in the wear rate was high initially. This was followed by a lower rate of decrease in the wear rate at longer traversal distances. The samples attained increasing wear rates at higher applied loads. The composites delineated lower wear rate compared to that of the matrix alloy; increasing $\mathrm{TiC}$ content led to a further reduction in the wear rate.

Temperature near the contacting surface of the samples is shown in Fig. 5. The frictional heating rose with increasing traversal distance. The rate of temperature increase was high initially followed by a reduced rate of temperature rise at longer traversal distances. The severity of frictional heating decreased in the case of the composites over that of the matrix alloy. Further, increasing TiC content 


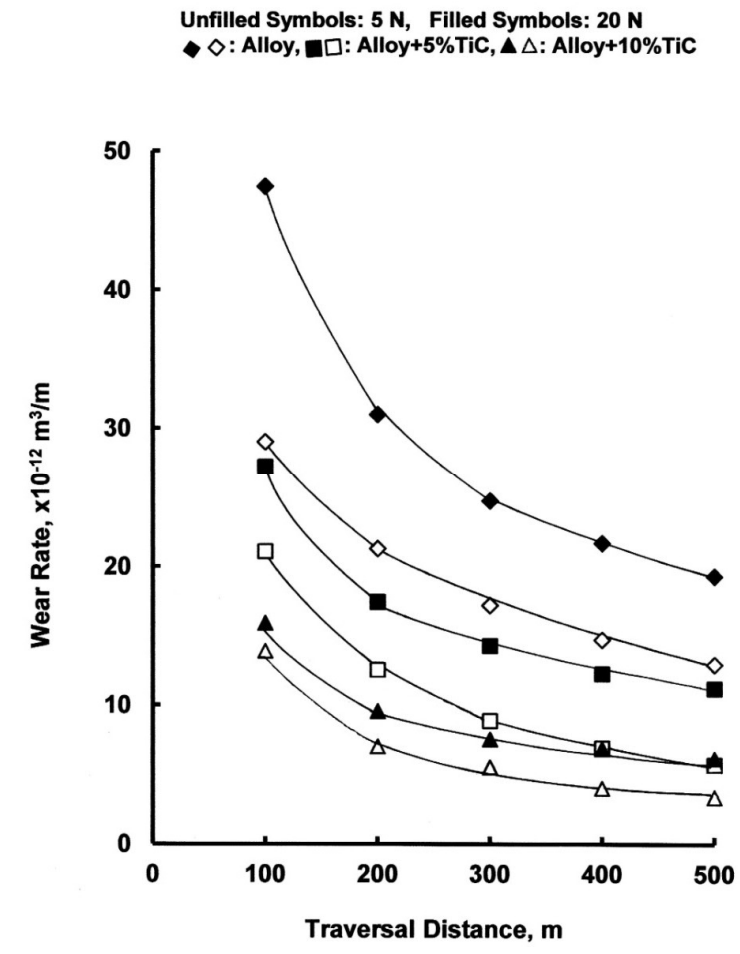

Fig. 4 Wear rate plotted as a function of traversal distance at different applied loads in the case of the matrix alloy and composites containing TiC particles

brought about still less frictional heating. Increasing load caused the realization of a greater severity of frictional heating. Moreover, the influence of $\mathrm{TiC}$ reinforcement and its content as well as traversal distance on temperature became more prominent at the higher applied load.

Friction coefficient of the samples increased significantly with the traversal distance at lower distances (Fig. 6). The rate of increase in the property became considerably small and the samples rather attained a steady state condition at longer traversal distances. In some cases, it decreased slightly before attaining the steady state friction coefficient. The friction coefficient reduced in case of the composites over that of the matrix alloy, increasing TiC content in the matrix leading to still less friction coefficient. Moreover, increasing load led to a reduction in the friction coefficient except in the case of the composite containing the highest concentration of $\mathrm{TiC}$ particles, the trend reversed in the latter case.

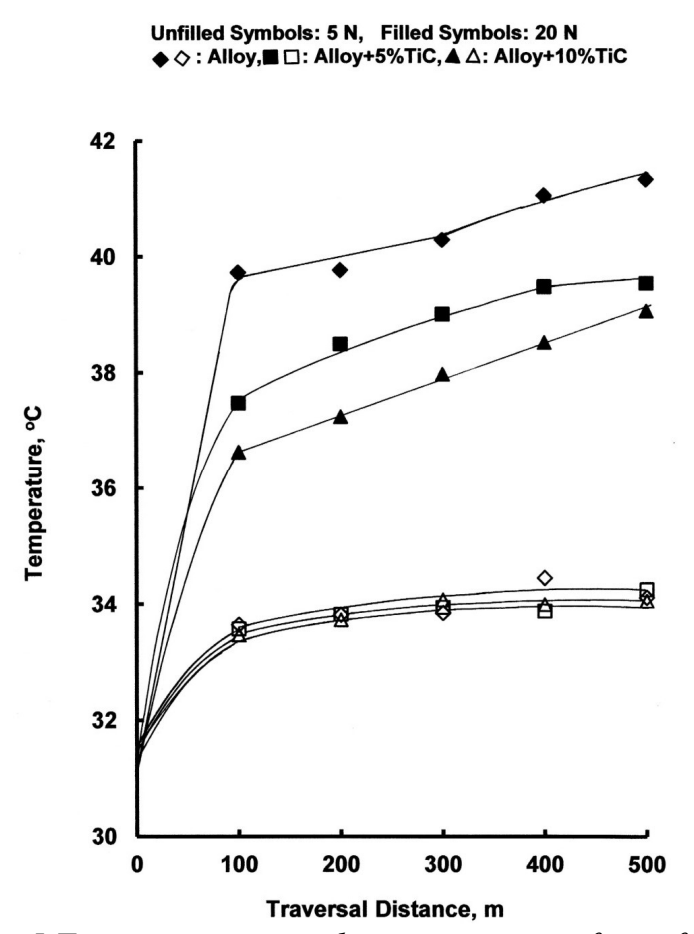

Fig. 5 Temperature near the contacting surface of the samples plotted as a function of traversal distance at different applied loads in the case of the matrix alloy and composites containing TiC particles

Unfilled Symbols: $5 \mathrm{~N}$, Filled Symbols: $20 \mathrm{~N}$

$\diamond \diamond:$ Alloy, $\square$ : Alloy+5\%TiC, $\triangle$ : Alloy+10\%Tic

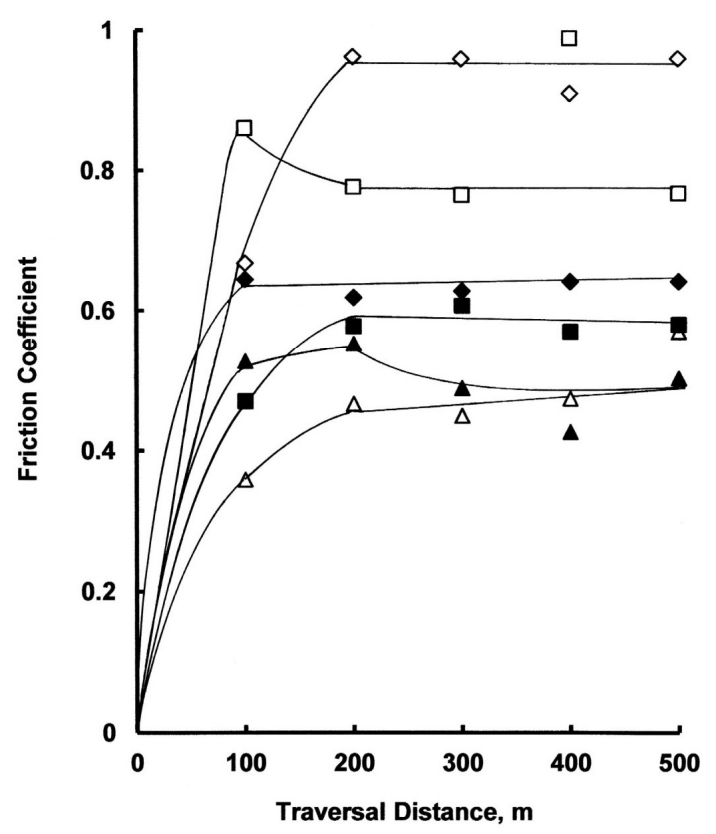

Fig. 6 Friction coefficient plotted as a function of traversal distance at different applied loads in the case of the matrix alloy and composites containing TiC particles 


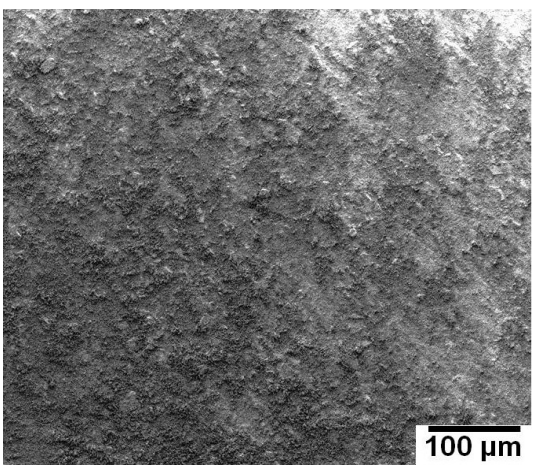

(a)

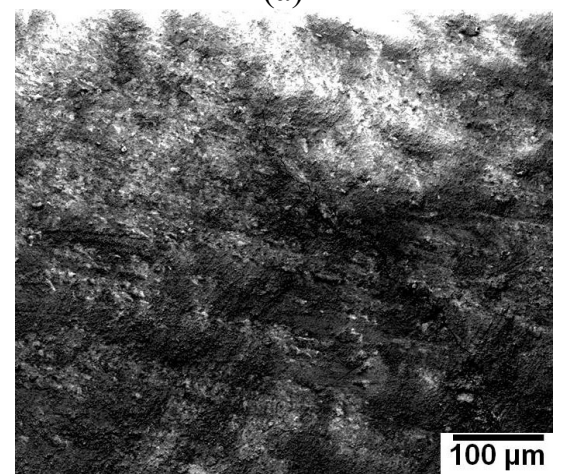

(c)

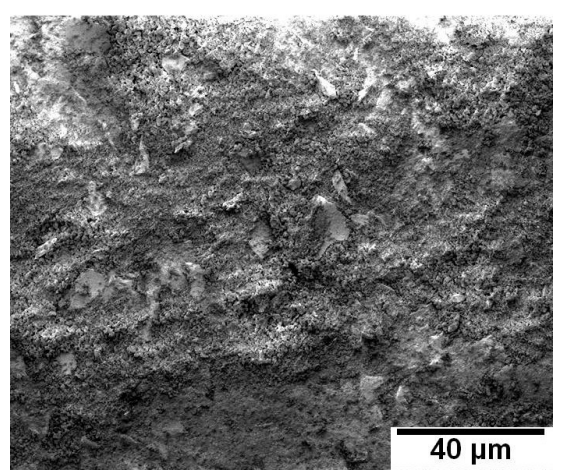

(b)

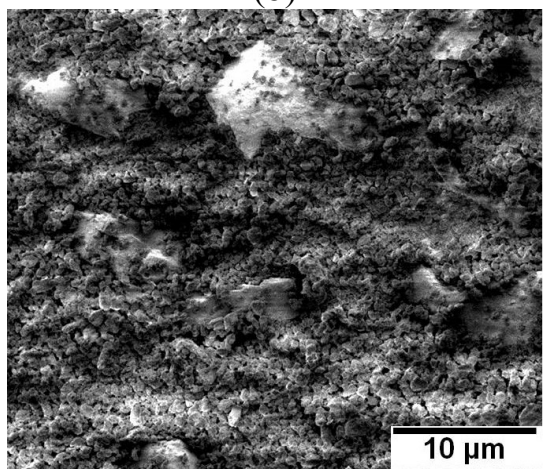

(d)

Fig. 7 Features of the abrasive medium after testing the matrix alloy for $500 \mathrm{~m}$ traversal distance at the applied loads of $(a \& b) 5$ and $(c \& d) 20 \mathrm{~N}$

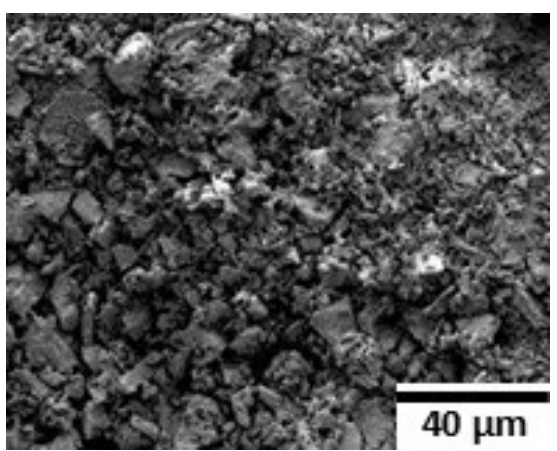

(a)

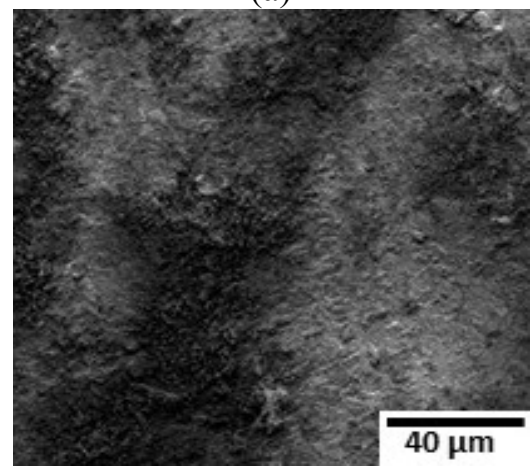

(c)

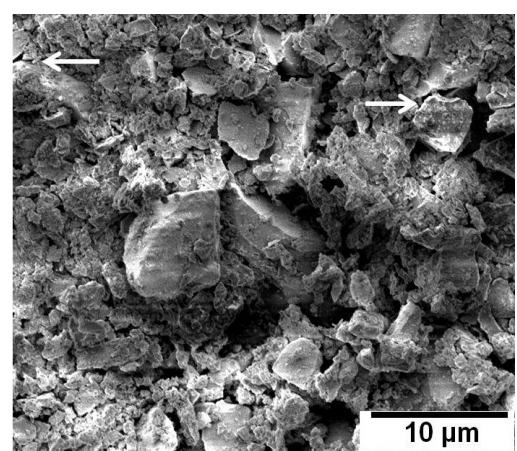

(b)

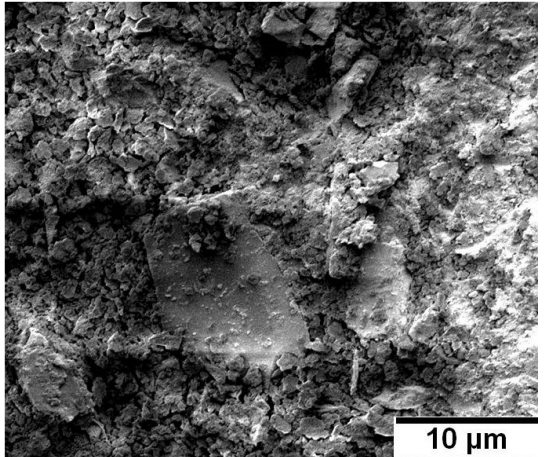

(d)

Fig. 8 Features of the abrasive medium after testing the composite containing $10 \%$ TiC particles for $500 \mathrm{~m}$ traversal distance at the applied loads of $(a \& b) 5$ and $(c \& d) 20 \mathrm{~N}$ [Arrow: fracture of abrasive particles] 


\section{Abrasive Medium}

Figure 7 shows the abrasive medium after testing the matrix alloy. Sticking of debris on and around the abrasive particles was noted in general. Magnified views clearly show these events (Fig. 7b\&d). Blunting of the abrasive particles was also noted after abrading the samples (Fig. $7 \mathrm{a} \& \mathrm{c}$ versus $1 \mathrm{a}$ and $7 \mathrm{~b}$ versus 1b). The degree of blunting and severity of sticking/entrapment of debris increased significantly with increasing load (Fig. 7c versus a). A practically similar trend was also observed as far as the characteristics of the abrasive medium after testing the composites is concerned (Fig. 8). However, the degree of blunting in the case of abrading the composites was somewhat higher than that of the matrix alloy (Fig. 8d versus 7d). A magnified view reveals fracturing/cracking of the (abrasive) particles (Fig. 8b, regions marked by arrow) in addition to that of debris sticking and entrapment.

\section{Wear Surfaces}

Wear surfaces of the alloy are shown in Fig. 9. Sticking of debris/ fragmented abrasive particles was there on the wear surfaces (Fig. $9 \mathrm{c}$, regions marked by arrow). Similar were the features of the wear surfaces of the composites (Fig. 10). However, the wear surfaces of the composites were relatively smoother than that of the matrix alloy (Fig. 10a versus 9a). Further, the depth of the wear grooves was relatively less in the regions containing the reinforcement TiC particles (Fig. 10c). The dispersoid $\mathrm{TiC}$ particles were observed to be exposed on to the abraded surfaces (Fig. $10 \mathrm{~b} \& \mathrm{~d}$, regions marked by A). Moreover, the grooves became coarser with increasing load (Fig. 10c versus a).

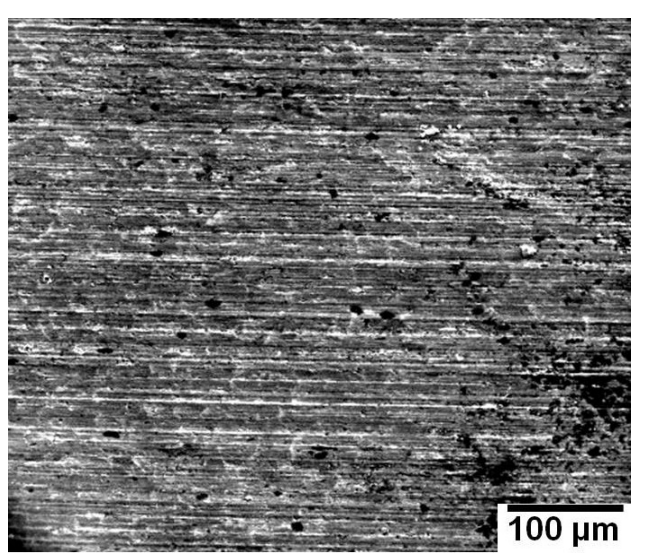

(a)

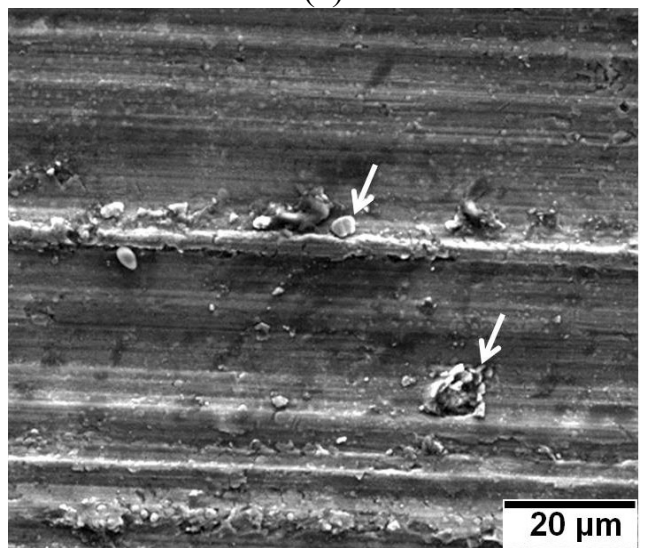

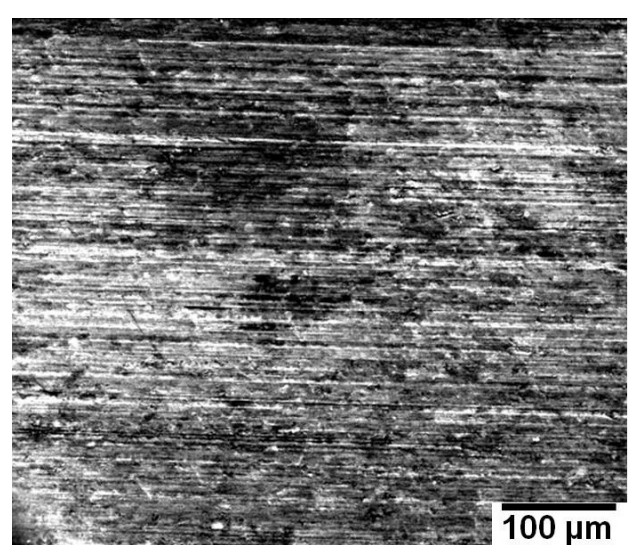

(b)

(c)

Fig. 9 Features of the abraded surfaces of the matrix alloy after testing for $500 \mathrm{~m}$ traversal distance at the applied loads of (a) 5 and $(b \& c) 20 \mathrm{~N}$ [Arrow: entrapped abrasive/debris particles] 


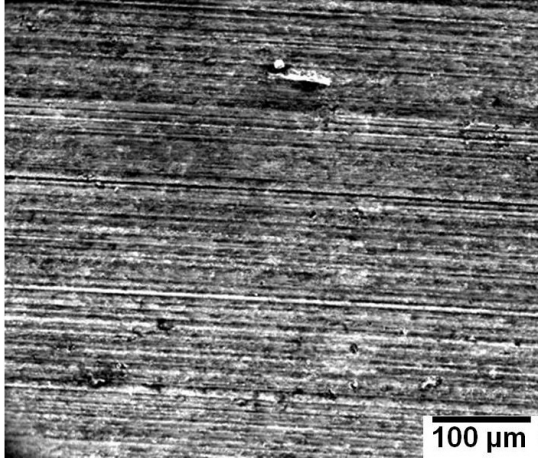

(a)

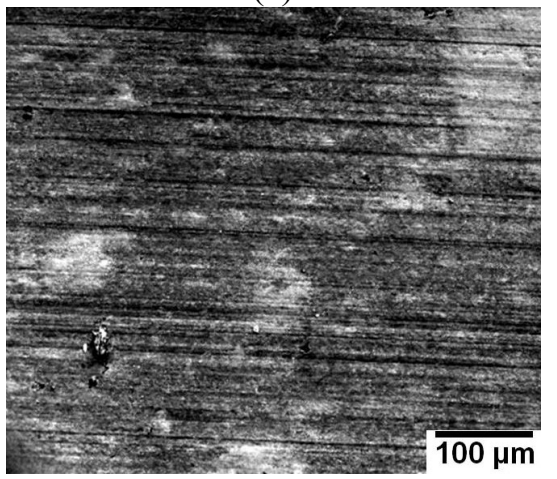

(c)

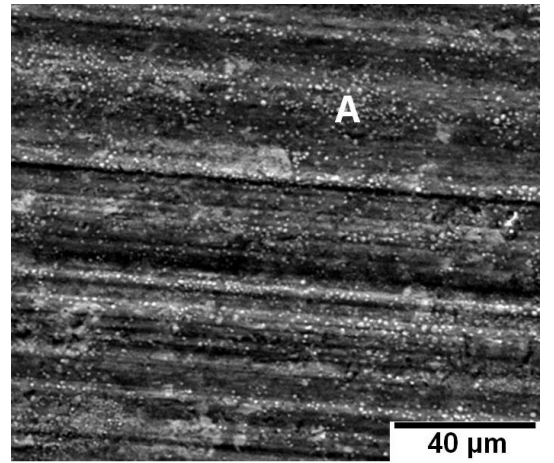

(b)

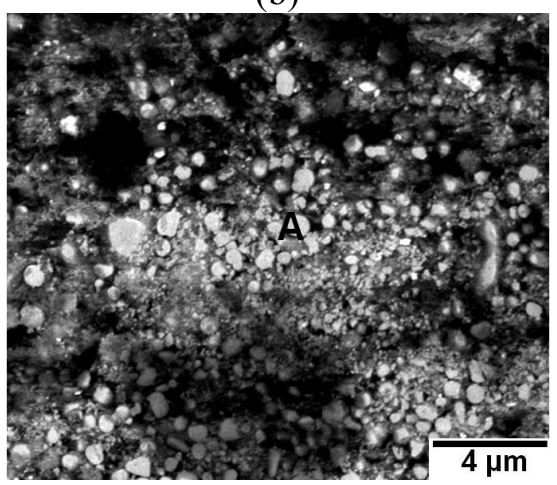

(d)

Fig. 10 Features of the abraded surfaces of the composite containing 10\%TiC particles after testing for 500 $m$ traversal distance at the applied loads of $(a \& b) 5$ and $(c \& d) 20 N$ [A: exposed reinforcement phase]

\section{$\underline{\text { Subsurface Regions }}$}

Figure 11 shows the regions below the abraded surfaces of the matrix alloy. Regions in a process of being separated from the bulk were observed in general (Fig. 11a\&c, regions marked by single arrow). A magnified view shows negligible wear induced plastic deformation of the regions in the nearest vicinity of the wear surface as evident from their identical microstructural features to that of the bulk (Fig. 11d, regions marked by A and $\mathrm{B}$ respectively). The presence of microcracks was also observed (Fig. 11b-d, regions marked by double arrow). Entrapment of a fragmented abrasive particle may be noted in Fig. 11b (region marked by triple arrow). The thickness of the region attached to the bulk became greater with increasing load (Fig. 11c\&d versus $\mathrm{a} \& \mathrm{~b}$ respectively). A similar trend was also observed in case of the composite (Fig. 12). Fragmented abrasive particles entrapped in the near vicinity of the wear surface were observed in this case too (Fig. 12b, region marked by A).

\section{DISCUSSION}

Dispersion of fine second phase particles in alloy matrices has been a matter of great concern in view of associated problems like segregation of the dispersoid phase and generation of more porosity. There are other issues involved in the case of fine dispersoid phases such as handling problems and health hazards due to limitation of arresting their inhalation during handling/operation as discussed earlier. In this context, the presently adopted hybrid in-situ technique [95] for synthesizing the composites seems to be useful since it incorporates the benefits of both the powder and liquid metallurgy routes. Good dispersoid/matrix bonding and the formation of fine $\mathrm{TiC}$ particles in the size range of 


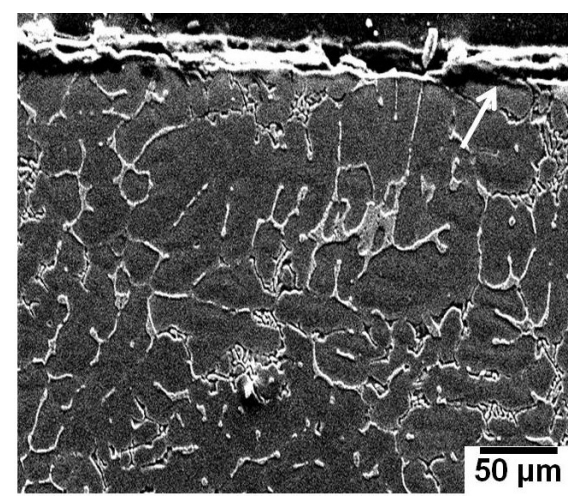

(a)

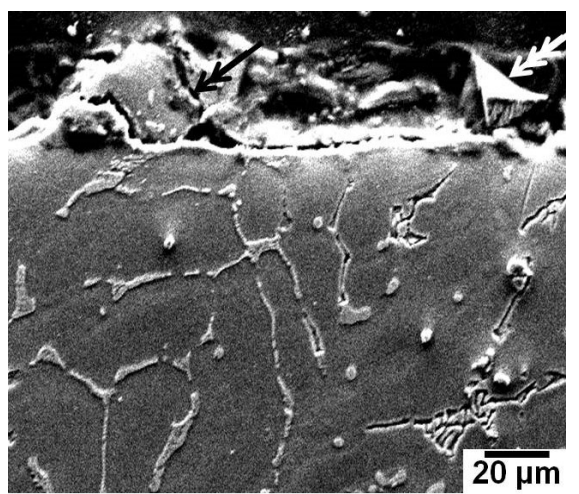

(b)

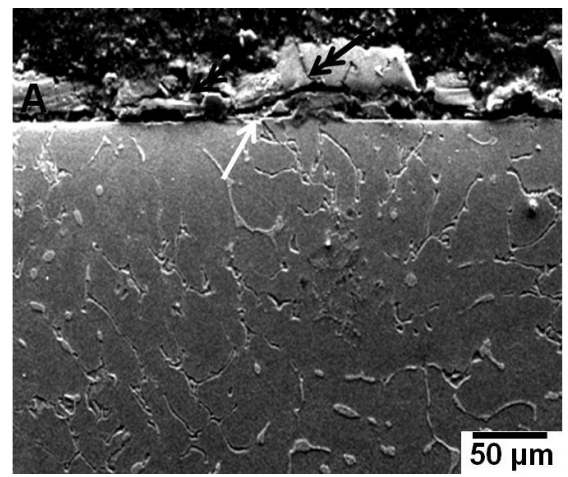

(c)

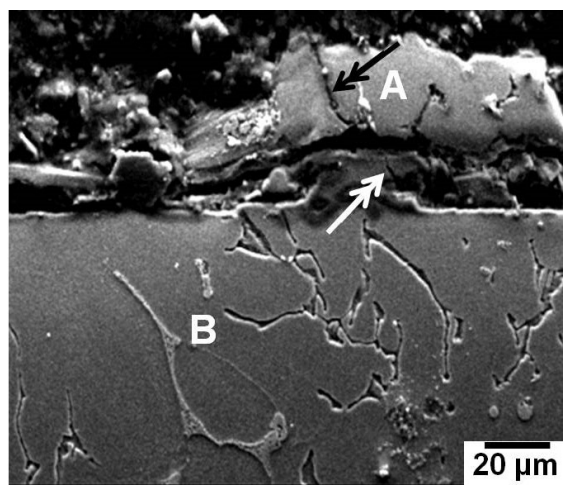

(d)

Fig. 11 Features of the subsurface regions in case of the matrix alloy after testing for $500 \mathrm{~m}$ traversal distance at the applied loads of $(a \& b) 5$ and $(c \& d) 20 N$ [Single arrow: regions in a process of being separated from the bulk, double arrow: microcracks, triple arrow: entrapped abrasive particle, A: region in the nearest vicinity of the wear surface and B: bulk region away from the wear surface]
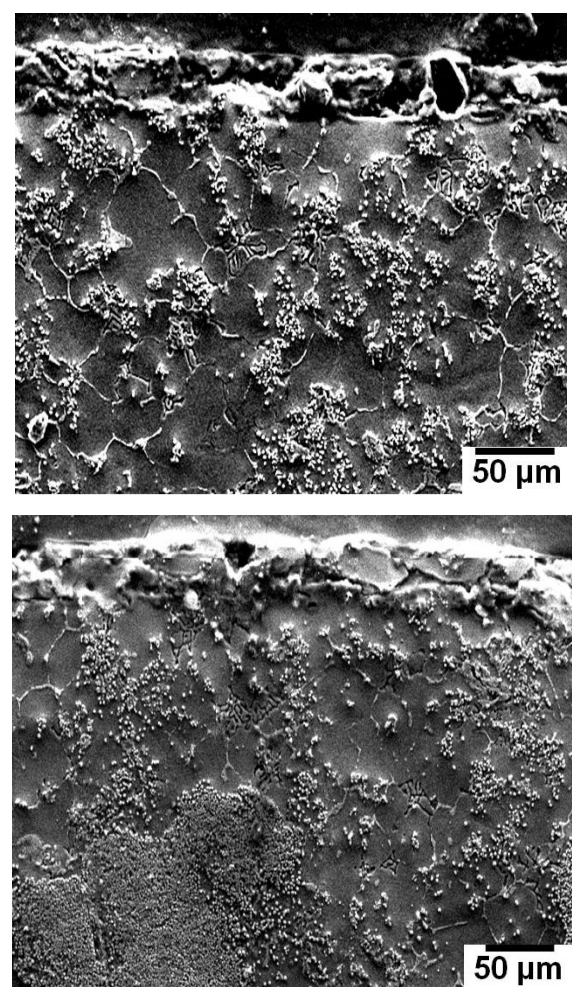

(a)

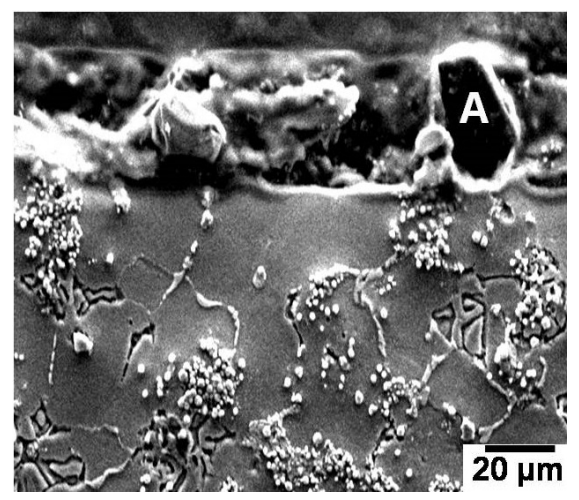

(c)

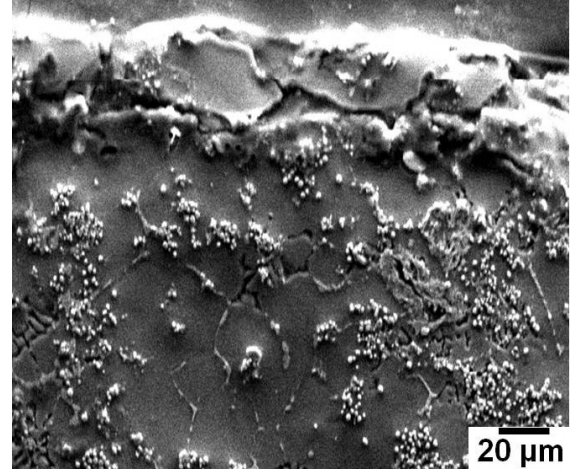

(b)

(d)

Fig. 12 Features of the subsurface regions in case of the composite containing $10 \%$ TiC particles after testing for $500 \mathrm{~m}$ traversal distance at the applied loads of ( $a \& b) 5$ and $(c \& d) 20 \mathrm{~N}$ [A: entrapped abrasive particle] 
submicron to $\sim 4 \mu \mathrm{m}$ in the matrix (Fig. $3 \mathrm{c} \& \mathrm{~d}$ ) suggests the attainment of desirable results.

During two-body abrasion, the abrasive particles are firmly bonded on to the strong paper base that in turn is rigidly fixed on the counterface/disc. In the event of abrading MMCs, the abrasive particles have to encounter the reinforcement particles in view of the fixed depth condition maintained in such cases since the former do not have the freedom to bounce back [78-80,89,90]. Accordingly, the depth of penetration becomes the same irrespective of the hardness of the constituent phases of the samples. This enables the reinforced hard microconstituents/ reinforcements to protect the softer phases against the penetrating action of the abrasive particles more effectively. The abrasive particles behave as a cutting tool in this case in view of their firm bonding on the paper base and also on the counterface. In the process of penetration against the material surface, the debris particles get entrapped/ stuck on and around the abrasive particles, the processes being known as capping and clogging respectively $[79,96]$. The abrasive particles also get blunted because of the rubbing action while their fragmentation takes place as a result of the two-body (high-stress) condition generated therein $[79,96]$. Cracking and fragmentation of the abrasive particles generate sharp corners and edges while their degree of protrusion reduces $[78,96]$. Thus, fragmentation leads to a mixed influence on the extent of wear loss in the sense that the generation of sharp corners causes higher loss in view of larger depth of penetration while a reduction in the degree/level of protrusion produces a reverse effect because of the decreased severity of penetration. Accordingly, the net effect of fragmentation and cracking on the wear loss depends on whether the influence of the generation of sharp corners and edges on the decreased level of protrusion dominates or vice versa. To summarize, processes like capping, clogging and blunting (attrition) lead to less material loss while fragmentation produces a mixed effect $[78-80,89,90,96]$. Work hardening of the subsurface regions has also been reported to cause less wear loss/rate [82,83]. However, this factor does not seem to play any effective role in the present investigation in view of practically identical microstructural features of the regions in the near vicinity of and away from the wear surface (Fig.11d, region marked by $\mathrm{A}$ and $\mathrm{B}$ respectively), thus signifying negligible wear induced plastic deformation/ work hardening.

Improved wear resistance (inverse of wear rate) of the composites could be attributed to the resistance offered by the $\mathrm{TiC}$ particles (reinforced in the alloy matrix) against the destructive action of the abrasive ( $\mathrm{SiC}$ ) particles. The relatively smoother wear surfaces of the composites than that of the matrix alloy (Fig. 10a versus 9a) and a somewhat higher degree of attrition of the abrasive particles in the case of testing the composites (Fig. 8d versus 7d) further substantiate the observed wear response of the samples. Higher wear rate of the samples with increasing applied load could be due to larger depth of penetration of the abrasive particles as also observed in terms of deeper/coarser wear grooves (Fig. 10c versus a). A higher degree of frictional heating with rising load (Fig. 5) could be attributed to the increasing severity of wear condition and greater depth of penetration as also evident from the deeper wear grooves (Fig. 10c versus a). However, a corresponding decrease in friction coefficient with more severe loading condition (Fig. 6) could be owing to the reduced cracking tendency of the material system [97] under the condition of higher frictional heating (Fig. 5). It may be mentioned that the interfacial cracking tendency dominates at low temperatures leading to the additional abrasive action of the removed mass that gets entrapped in between the sliding surfaces subsequent to its fragmentation and release and hence higher 
friction coefficient $[97,98]$. On the contrary, the trend reverses at higher temperatures (within limits) in view of improved compatibility of the matrix with the dispersed phases thus reducing the cracking tendency of the material system [97]. Under the circumstances, the severity of removal of the dispersoid phase decreases thus causing improved protection to the softer matrix and less abrasive action and hence reduction in the friction coefficient at higher loads (Fig. 6). A high rate of increase in the severity of frictional heating and friction coefficient with traversal distance initially (Fig. 5 and 6 respectively) could be attributed to a higher degree of abrasive action caused by the highly protruding fresh abrasive particles (Fig. 1) as well as additional abrasive action caused by the fragmented abrasive/ hard debris particles [99]. With the increasing traversal distance, the degree of attrition (blunting) of the abrasive particles increases, thus bringing about a relatively less severity of increase in the properties. The net influence of fragmentation of the abrasive particles depends on the nature of predominance of the counterbalancing effects of the two parameters as discussed earlier. Rest of the factors like capping and clogging actions taking place as a result of covering by and entrapment of the debris in between the abrasive particles (Fig. 7\&8) brings about a reduction in the cutting efficiency of the abrasive medium and hence less severity of material removal. It has been observed that capping, clogging and attrition play a more dominant role in controlling the severity of material loss/ damage compared to that of the matrix work hardening, the latter playing a secondary role in view of limited wear induced plastic deformation (Fig. 11\&12) as also evident from a correspondingly low overall rise in frictional heating (Fig. 5).

The presence of entrapped hard debris particles on the abraded surfaces of the samples (Fig. 9c, arrow marked region) produces additional cutting action leading to more severe damage to the surface. Further, the exposure of the dispersed TiC particles on the abraded surfaces of the composites (Fig. 10d) suggests their active participation towards resisting the destructive action of the abrasive medium and hence improved wear resistance (inverse of wear rate) compared to that of the matrix alloy (Fig. 4).

Negligible wear induced plastic deformation in the near vicinity of the wear surface, as evident from practically identical microstructural features of the regions in a process of separation from the bulk and the bulk below (Fig. 11c\&d) results from the fast cutting action of the abrasive particles thus not allowing the material to interact well with the (abrasive) medium. This is also in agreement with correspondingly limited increase in frictional heating (Fig. 5).

\section{CONCLUSIONS}

1. The in-situ process adopted in this study enabled to disperse fine $\mathrm{TiC}$ particles in the Al alloy matrix with sound dispersoid/matrix interfacial bonding.

2. The composites attained decreased abrasive wear rate and frictional heating over that of the matrix alloy. Moreover, increasing dispersoid (TiC) content proved to be further beneficial in this context.

3. Increasing load brought about a reduction in the friction coefficient except in the case of the composite with the highest TiC content; the trend reversed in the latter case.

4. The wear rate decreased with increasing traversal distance while applied load produced a reverse effect.

5. The frictional heating (temperature near the contacting surface of the samples) 
increased with rising traversal distance. Also, the severity of the increase became more prominent at a higher applied load.

6. The friction coefficient generally increased with increasing traversal distance. However, a practically steady state condition was attained at longer traversal distances while a reduction in friction coefficient after attaining the peak was noticed in some cases.

7. Capping, clogging and attrition were found to be important material removal mechanisms. Cracking and fragmentation of the abrasive ( $\mathrm{SiC}$ ) particles were also noticed to a limited extent while the dispersoid (TiC) particles remained intact in the alloy matrix protecting the specimen surface during the process of abrasion.

\section{REFERENCES}

1. W. Wang, P. Shi, M. Qi, J.J. Xu, F.X. Chen and D.Z. Yang, Dry sliding wear of a $\mathrm{Ti}_{50} \mathrm{Ni}_{25} \mathrm{Cu}_{25}$ particulate-reinforced aluminum matrix composite, Metall. Mater. Trans. A, 29A(1998)1741-1747. https://doi.org/10.1007/s11661-998-0097-y

2. H. Kaftelen, N. Unlu, G. Goller, M.L. Ovecoglu and H. Henein, Comparative processing-structure-property studies of Al$\mathrm{Cu}$ matrix composites reinforced with $\mathrm{TiC}$ particulates, Composites: Part A, 42A(2011)812-824. https://doi.org/10.1016/j.compositesa.2011.0 3.016

3. M.J. Koczak, S.C. Khatri, J.E. Allison and M.G. Bader, Metal matrix composites for ground vehicle, aerospace and industrial applications, in: S. Suresh and A. Mortensen and A. Needleman (eds.), Fundamentals of Metal Matrix Composites, Amsterdam, Elsevier, 1993, pp. 297-312. https://doi.org/10.1016/B978-0-08-0523712.50020-1

4. K.B. Lee, H.S. Kim and H. Kwon, Reaction products of $\mathrm{Al} / \mathrm{TiC}$ composites fabricated by the pressureless infiltration technique. Metall. Mater. Trans. A, 36A(2005)25172527. https://doi.org/10.1007/s11661-0050125-0

5. S.V. Prasad and R. Asthana, Aluminum metal-matrix composites for automotive applications: tribological considerations, Tribo. Lett., 17(2004)445-452. https://doi.org/10.1023/B:TRIL.0000044492. 91991.f3

6. S. Das, Development of aluminium alloy composites for engineering applications, Trans. Indian Inst. Met., 57(2004)325-334.

7. P.K. Rohatgi, Cast aluminum matrix composites for automotive applications, JOM, 43(1991)10-15. https://doi.org/10.1007/BF03220538

8 . D.J. Lloyd, Particle reinforced aluminium and magnesium matrix composites, Int. Mater. Rev., 39(1994)1-23. https://doi.org/10.1179/imr.1994.39.1.1

9. A.E. Nitsham, New application for Al based MMC, Light Met. Age, 53(1997)53-54.

10. R.S. Rawal, Metal matrix composites for space applications, JOM, 53(2001)14-17. https://doi.org/10.1007/s11837-001-0139-z

11. A.R. Kennedy and S.M. Wyatt, The effect of processing on the mechanical properties and interfacial strength of aluminium $/ \mathrm{TiC}$ MMCs, Compos. Sci. Technol., 60(2000)307-314. https://doi.org/10.1016/S02663538(99)00125-6

12. S. Sheibani and F.M. Najafabadi, In-situ fabrication of Al-TiC metal matrix composites by reactive slag process, Mater. Des., 28(2007)2373-2378. https://doi.org/10.1016/j.matdes.2006.08.004

13. Z.S. Yu, R.F. Li and K. Qi, Joining of SiC particle reinforced aluminium metal matrix composites by electromagnetic field aided brazing method, Mater. Sci. Technol., 26(2010)695-698. https://doi.org/10.1179/174328409X430546

14. M.S. Song, M.X. Zhang, S.G. Zhang, B. Huang and G. Li, In-situ fabrication of $\mathrm{TiC}$ particulates locally reinforced aluminum matrix composites by self-propagating reaction during casting, Mater. Sci. Eng. A, $473 \mathrm{~A}(2008) 166-171$. https://doi.org/10.1016/j.msea.2007.03.086 
15. C.S. Ramesh, A. Ahamed, B.H. Channabasappa and R. Keshavamurthy, Development of $\mathrm{Al} 6063-\mathrm{TiB}_{2}$ in-situ composites, Mater. Des., 31(2010)22302236. https://doi.org/10.1016/j.matdes.2009.10.019

16. A. Yazdani and E. Salahinejad, Evolution of reinforcement distribution in $\mathrm{Al}-\mathrm{B}_{4} \mathrm{C}$ composites during accumulative roll bonding, Mater. Des., 32(2011)3137-3142. https://doi.org/10.1016/j.matdes.2011.02.063

17. N.G. Kumar, R. Narayanasamy, S. Natarajan, S.P. Babu, K. Sivaprasad and S. Sivasankaran, Dry sliding wear behaviour of AA $6351-\mathrm{ZrB}_{2}$ in-situ composite at room temperature, Mater. Des., 31(2010)15261532. https://doi.org/10.1016/j.matdes.2009.09.017

18. S. Chung and B.H. Hwang, A microstructural study of the wear behavior of $\mathrm{SiC} / \mathrm{Al}$ composites, Tribo. Int., 27(1994)307-314. https://doi.org/10.1016/0301679X(94)90024-8

19. M. Roy, B. Venkataraman, V.V. Bhanuprasad, Y.R. Mahajan and G. Sundararajan, The effect of particulate reinforcement on the sliding wear behavior of aluminium, Metall. Trans. A, 23A(1992)2833-2847. https://doi.org/10.1007/BF02651761

20. B. Venkataraman and G. Sundararajan, The sliding wear behaviour of $\mathrm{Al}-\mathrm{SiC}$ particulate composites I: macrobehavior, Acta Mater., 44(1996)451-460.

https://doi.org/10.1016/13596454(95)00217-0

21.H. Kaftelen, M.L. Ovecoglu, H. Henein and $\mathrm{H}$. Cimenoglu, $\mathrm{ZrC}$ particle reinforced $\mathrm{Al}-4$ wt. $\% \mathrm{Cu}$ alloy composites fabricated by mechanical alloying and vacuum hot pressing: microstructural evaluation and mechanical properties, Mater. Sci. Eng. A, 527A(2010)5930-5938. https://doi.org/10.1016/j.msea.2010.06.007

22. A. Mandal, M. Chakraborty and B.S. Murty, Effect of $\mathrm{TiB}_{2}$ particles on sliding wear behavior of $\mathrm{Al}-4 \mathrm{Cu}$ alloy, Wear, 262(2007)160-166. https://doi.org/10.1016/j.wear.2006.04.003

23. S.C. Tjong and Z.Y. Ma, Microstructural and mechanical characteristics of in-situ metal matrix composites, Mater. Sci. Eng. R, 29(2000)49-113. https://doi.org/10.1016/S0927796X(00)00024-3

24. X.W. Zeng, W.G. Zhang, N. Wei, R.P. Liu and M.Z. Ma, Preparation of in-situ $\mathrm{TiC}_{\mathrm{P}} / \mathrm{LY} 12$ composite and its microstructure and mechanical properties, Mater. Sci. Eng. A, 443A(2007)224-228. https://doi.org/10.1016/j.msea.2006.08.030

25. X.C. Tong and H.S. Fang, Al-TiC composites in-situ processed by ingot metallurgy and rapid solidification technology: part I - microstructural evolution, Metall. Mater. Trans. A, 29A(1998)875-891. https://doi.org/10.1007/s11661-998-0278-8

26. P.K. Rohatgi, R. Asthana and S. Das, Solidification, structures and properties of cast metal-ceramic particle composites. Int. Metal. Rev., 31(1986)115-139. https://doi.org/10.1179/imtr.1986.31.1.115

27. S. Jerome, B. Ravisankar, P.K. Mahato and S. Natarajan, Synthesis and evaluation of mechanical and high temperature tribological properties of in-situ $\mathrm{Al}-\mathrm{TiC}$ composites, Tribo. Int., 43(2010)2029-2036. https://doi.org/10.1016/j.triboint.2010.05.007

28. A. Kumar, M.M. Mahapatra and P.K. Jha, Modelling the abrasive wear characteristics of in-situ synthesized $\mathrm{Al}-4.5 \% \mathrm{Cu} / \mathrm{TiC}$ composites, Wear, 306(2013)170-178. https://doi.org/10.1016/j.wear.2013.08.013

29. M.G. Chu and M.K. Premkumar, Mechanism of $\mathrm{TiC}$ formation in $\mathrm{Al} / \mathrm{TiC}$ in-situ metal matrix composites, Metall. Trans. A, 24A(1993)2803-2805. https://doi.org/10.1007/BF02659503

30. M.N. Wahab, A.R. Daud and M.J. Ghazali, Preparation and characterization of stir cast aluminium nitride reinforced aluminium metal matrix composites, Int. J. Mech. Mater. Eng., 4(2009)115-117.

31. S.V. Prasad and P.K. Rohatgi, Tribological properties of $\mathrm{Al}$ alloy particle composites, $\mathrm{J}$. Met., 39(1987)22-26. https://doi.org/10.1007/BF03257531

32. B.S. Mazumder, A.H. Yegneswaran and P.K. Rohatgi, Strength and fracture behaviour of metal matrix particulate composites, Mater. Sci. Eng. A., 68(1984)85-96. 
https://doi.org/10.1016/00255416(84)90246-5

33. B.K. Prasad and S. Das, The significance of matrix microstructure on the solid lubrication characteristics of graphite in aluminium alloys, Mater. Sci. Eng. A, 144A(1991)229-235.

https://doi.org/10.1016/09215093(91)90229-G

34. Q. Wu, C. Yang, F. Xue and Y. Sun, Effect of Mo addition on the microstructure and wear resistance of in-situ $\mathrm{TiC} / \mathrm{Al}$ composite, Mater. Des., 32(2011)4999-5003. https://doi.org/10.1016/j.matdes.2011.06.045

35. M. Gui, D. Wang, J. Wu and C. Li, Erosion of in-situ TiC particle reinforced $\mathrm{Al}-5 \mathrm{Cu}$ composite, Mater. Res. Bull., 36(2001)15731585. https://doi.org/10.1016/S00255408(01)00485-8

36. E. Rabinowicz and A. Mutis, Effect of abrasive particle size on wear, Wear, 8(1965)381-390.

https://doi.org/10.1016/00431648(65)90169-9

37. R. Bauri, Synthesis of Al-TiC in-situ composites: effect of processing temperature and $\mathrm{Ti}: \mathrm{C}$ ratio, Trans. Indian Inst. Met., 62(2009)391-395.

https://doi.org/10.1007/s12666-009-0068-z

38. P. Sahoo and M.J. Kozak, Microstructureproperty relationships of in-situ reacted $\mathrm{TiC} /$ Al-Cu metal matrix composites, Mater. Sci. Eng. A, 131A(1991)69-76.

https://doi.org/10.1016/09215093(91)90345-N

39. R. Tyagi, Synthesis and tribological characterization of in situ cast Al-TiC composites, Wear 259(2005)569-576. https://doi.org/10.1016/j.wear.2005.01.051

40. Y.Y. Wei, F.Z. Yi and Y.R. Zhang, The combustion synthesis process of Al-Ti-C system in an elevated-temperature Al-melt, Chem. Mater. Sci., 17(2002)13-16.

41. I. Gotman, M.J. Koczak and E. Shtessel, Fabrication of Al matrix in-situ composites via self-propagating synthesis, Mater. Sci. Eng. A, 187A(1994)189-199. https://doi.org/10.1016/09215093(94)90347-6

42. A. Albiter, A. Contreras, M. Salazar and J.G. Gonzales-Rodriguez, Corrosion behavior of aluminium metal matrix composites reinforced with $\mathrm{TiC}$ processed by pressureless melt infiltration. J. Appl. Electrochem., 36(2006)303-308. https://doi.org/10.1007/s10800-005-9073-Z

43. A.R. Kennedy, A.E. Karantzalis and S.M. Wyatt, The microstructure and mechanical properties of $\mathrm{TiC}$ and $\mathrm{TiB}_{2}$-reinforced cast metal matrix composites, J. Mater. Sci., 34(1999)933-940. https://doi.org/10.1023/A:1004519306186

44. V.H. Lopez, A. Scoles and A.R. Kennedy, The thermal stability of TiC particles in an Al 7 wt.\% Si alloy, Mater. Sci. Eng. A, 356A(2003)316-325.

https://doi.org/10.1016/S09215093(03)00143-6

45. B.S. Yigezu, P.K. Jha and M.M. Mahapatra, Effect of sliding distance, applied load, and weight percentage of reinforcement on the abrasive wear properties of in-situ synthesized Al-12\% $\mathrm{Si} / \mathrm{TiC}$ composites, Tribo. Trans., 56(2013)546-554. https://doi.org/10.1080/10402004.2013.7674 $\underline{01}$

46. C. Cui, Y. Shen, F. Meng and S.B. Kang, Review on fabrication method of in-situ metal matrix composites, J. Mater. Sci. Technol., 16(2000)619-626. https://doi.org/jmst.org/CN/Y2000/V16/I06/ $\underline{619}$

47. B.S.S. Daniel, V.S.R. Murthy and G.S. Murty, Metal-ceramic composites via in-situ methods, J. Mater. Process. Technol., 68(1997)132-155.

https://doi.org/10.1016/S09240136(96)00020-9

48. M.K. Premkumar and M.G. Chu, Al-TiC particulate composite produced by a liquid state in-situ process, Mater. Sci. Eng. A, 202A(1995) 172-178.

https://doi.org/10.1016/09215093(95)09787-2

49. P. Li, E.G. Kandalova and V.I. Nikitin, Insitu synthesis of Al-TiC in aluminium melt, Mater. Lett., 59(2005)2545-2548. https://doi.org/10.1016/j.matlet.2005.03.043

50. M.A. Doheim, A.M. Omran, A.A. Gwad and G.A. Sayed, Evaluation of Al-Ti-C master alloys as grain refiner for aluminum and its alloys, Metall. Mater. Trans. A, 
$42 \mathrm{~A}(2011) 2862-2867$.

https://doi.org/10.1007/s11661-011-0689-9

51. C. Raghunath, M.S. Bhat and P.K. Rohatgi, In-situ technique for synthesizing Fe-TiC composites, Scri. Metall. Mater., 32(1995)577-585.

https://doi.org/10.1016/0956716X(95)90840-G

52. Y. Sahin, Preparation and some properties of $\mathrm{SiC}$ particle reinforced aluminium alloy composites, Mater. Des., 24(2003)671-679. https://doi.org/10.1016/S02613069(03)00156-0

53. A.R. Kennedy and S.M. Wyatt, Characterizing particle-matrix interfacial bonding in particulate $\mathrm{Al}-\mathrm{TiC}$ MMCs produced by different methods, Composites Part A, 32A(2001)555-559. https://doi.org/10.1016/S1359835X(00)00052-X

54. H.S. Lee, J.S. Yeo, S.H. Hong, D.J. Yoon and K.H. Na, The fabrication process and mechanical properties of $\mathrm{SiCp} / \mathrm{Al}-\mathrm{Si}$ metal matrix composites for automobile airconditioner compressor pistons, J. Mater. Process. Technol., 113(2001)202-208. https://doi.org/10.1016/S09240136(01)00680-X

55. M. Vedani, E. Gariboldi, G. Silva and G.C. $\mathrm{Di}$, Influence of interface properties on mechanical behavior of particle reinforced metal matrix composites, Mater. Sci. Technol., 10(1994)132-140. https://doi.org/10.1179/mst.1994.10.2.132

56. A.R. Kennedy, D.P. Weston and M.I. Jones, Reaction in Al-TiC metal matrix composites, Mater. Sci. Eng. A, 316A(2001)32-38. https://doi.org/10.1016/S09215093(01)01228-X

57. R.N. Rai, G.L. Datta, M. Chakraborty and A.B. Chattopadhyay, A study on the machinability behaviour of Al-TiC composite prepared by in-situ technique, Mater. Sci. Eng. A, 428A(2006)34-40. https://doi.org/10.1016/j.msea.2005.11.040

58. A.B. Padney, R.S. Mishra and Y.R. Mahajan, Effect of isothermal heat treatment on the creep behaviour of an Al-TiCp composite, Mater. Sci. Eng. A, 206A(1996)270-278. https://doi.org/10.1016/0921$\underline{\text { 5093(95)09998-0 }}$
59. W.H. Jiang, G.H. Song, X.L. Han, C.L. He and H.C. Ru, Synthesis of TiC/Al

composites in liquid aluminium, Mater. Lett., 32(1997)63-65.

https://doi.org/10.1016/S0167577X(97)00011-6

60. P. Li, E.G. Kandalova, V.I. Nikitin, A.G. Makarenko, A.R. Luts and Z. Yanfei, Preparation of Al-TiC composites by selfpropagating high-temperature synthesis, Scri. Mater., 49(2003)699-703. https://doi.org/10.1016/S13596462(03)00402-0

61. P.H. Shipway, A.R. Kennedy and A.J. Wilkes, Sliding wear behaviour of aluminium-based metal matrix composites produced by a novel liquid route, Wear, 216(1998)160-171. https://doi.org/10.1016/S00431648(97)00153-1

62. E. Karantzalis, S. Wyatt and A.R. Kennedy, The mechanical properties of Al-TiC metal matrix composites fabricated by a fluxcasting technique, Mater. Sci. Eng. A, 237A(1997)200-206. https://doi.org/10.1016/S09215093(97)00290-6

63. I. Ibrahim, F.A. Mohamed and E.J. Lavernia, Particulate reinforced metal matrix composites - a review, J. Mater. Sci., 26(1991)1137-1156. https://doi.org/10.1007/BF00544448

64. R.N. Rai, G.L. Datta and M. Chakraborty, High temperature synthesis and characterization of $\mathrm{Al}-\mathrm{TiC}$ composites to commercialize for foundry practice, in: Proc. WFC-2004, Vol. 2, Istanbul, Turkey, 2004, pp. 1339-1348.

65. B. Yang, G. Chen and J. Zhang, Effect of $\mathrm{Ti} / \mathrm{C}$ additions on the formation of $\mathrm{Al}_{3} \mathrm{Ti}$ of in-situ TiC/Al composites, Mater. Des., 22(2001)645-650. https://doi.org/10.1016/S02613069(01)00029-2

66. A.R. Kennedy, D.P. Weston, M.I. Jones and C. Enel, Reaction in Al-Ti-C powders and its relation to the formation and stability of $\mathrm{TiC}$ in $\mathrm{Al}$ at high temperatures, Scri. Mater., 42(2000)1187-1192. https://doi.org/10.1016/S1359$\underline{6462(00) 00356-0}$ 
67. Y. Birol, Grain refining efficiency of Al-TiC alloys, J. Alloys Compd., 422(2006)128131.

https://doi.org/10.1016/j.jallcom.2005.11.059

68. G.S.V. Kumar, B.S. Murty and M. Chakraborty, Development of Al-Ti-C grain refiners and study of their efficiency on $\mathrm{Al}$ and Al-7Si alloy, J. Alloys Compd., 396(2005)143-150.

https://doi.org/10.1016/j.jallcom.2004.12.039

69. M.K. Surappa, S.V. Prasad, and P.K.

Rohatgi, Wear and abrasion of cast Alalumina particle composites, Wear, 77(1982)295-302.

https://doi.org/10.1016/0043$\underline{1648(82) 90055-2}$

70. H. Ahlatci, E. Candan and H. Cimenoglu, Abrasive wear behaviour and mechanical properties of $\mathrm{Al}-\mathrm{Si} / \mathrm{SiC}$ composites, Wear, 257(2004)625-632.

https://doi.org/10.1016/j.wear.2004.03.006

71. W.Q. Song, P. Krauklis, A.P. Mouritz and S. Bandyopadhyay, The effect of thermal ageing on the abrasive wear behaviour of age hardening $2014 \mathrm{Al} / \mathrm{SiC}$ and $6061 \mathrm{Al} / \mathrm{SiC}$ composites, Wear, 185(1995)125-130. https://doi.org/10.1016/00431648(95)06599-7

72. A.K. Gupta and B.K. Prasad, Effects of microstructural features and test parameters on the abrasive wear response of Al-Si alloy, J. Mater. Eng. Perf., 22(2013)2089-2097. https://doi.org/10.1007/s11665-013-0474-6

73. A.K. Gupta, B.K. Prasad, R.K. Pajnoo and S. Das, Mechanical and abrasive and erosivecorrosive wear properties of eutectic Al-Si alloy: effects of T6 heat treatment parameter, Trans. Nonferrous Soc. China, 22(2012)1041-1050.

https://doi.org/10.1016/S10036326(11)61281-8

74. S. Das, D.P. Mondal, S. Sawla and N. Ramakrishnan, Synergistic effect of reinforcement and heat treatment on the twobody abrasive wear of an Al-Si alloy under varying loads and abrasive sizes, Wear, 264(2008)47-59. https://doi.org/10.1016/j.wear.2007.01.039

75. C.L. Xu, Y.F. Yang, H.Y. Wang and Q.C. Jiang, Effects of modification and heat treatment on the abrasive wear behaviour of hypereutectic Al-Si alloys, J. Mater. Sci., 42(2007)6331-6338. https://doi.org/10.1007/s10853-006-1189-y

76. S. Sawla and S. Das, Combined effect of reinforcement and heat treatment on the twobody abrasive wear of aluminium particle composites, Wear, 257(2004)555-561. https://doi.org/10.1016/j.wear.2004.02.001

77. D. Henryk and M. Maciej, Influence of grain refining on abrasive wear of submicron crystalline Al-Si alloys, Mater. Sci. Forum, 674(2011)97-103.

https://doi.org/10.4028/www.scientific.net/M SF.674.97

78. R. Dasgupta, B.K. Prasad, A.K. Jha, O.P. Modi, S. Das and A.H. Yegneswaran, Low stress abrasive wear behaviour of hardfaced steel, J. Mater. Eng. Perf., 7(1998)221-226. https://doi.org/10.1361/10599499877034795 $\underline{4}$

79. B.K. Prasad, S. Das, R. Dasgupta, O.P. Modi, A.K. Jha and A.H. Yegneswaran, Two-body abrasion characteristics of a zincbased alloy: Effects of SiC particle reinforcement and related factors, J. Mater. Sci. Lett., 17(1998)901-903. https://doi.org/10.1023/A:1026492001757

80. O.P. Modi, D.P. Mondal, B.K. Prasad, M. Singh and H.K. Khaira, Abrasive wear behaviour of a high carbon steel: Effect of microstructure and experimental parameters and correlation with mechanical properties, Mater. Sci. Eng. A, 343A(2002)235-242. https://doi.org/10.1016/S09215093(02)00384-2

81. Y. Sahin, Tribological behaviour of metal matrix and its composite, Mater. Des., 28(2007)1348-1352. https://doi.org/10.1016/j.matdes.2006.01.032

82. B.K. Prasad, S.V. Prasad and A.A. Das, Abrasion-induced microstructural changes and material removal mechanisms in squeeze cast aluminium alloy-silicon carbide composites, J. Mater. Sci., 27(1992)44894494. https://doi.org/10.1007/BF00541584

83. B.K. Prasad, S.V. Prasad and A.A. Das, Mechanisms of material removal and subsurface work hardening during low-stress abrasion of a squeeze cast aluminium alloyalumina fibre composite, Mater. Sci. Eng. A, 156A(1992)205-209. 
https://doi.org/10.1016/09215093(92)90152-Q

84. B.K. Prasad, K. Venkateswaralu, S. Das, A.K. Jha and R. Dasgupta, Influence of the $\mathrm{SiC}$ reinforcement on the abrasive wear response of an Al-Cu alloy under the conditions of varying abrasive size and applied load, J. Mater. Sci. Lett., 16(1997)1113-1115. https://doi.org/10.1023/A:1018567817509

85. Z. Hassan, R.K. Pandey and D.K. Sehgal, Wear characteristics in Al-SiC particulate composites and the Al-Si piston alloy, J. Min. Mater. Character. Eng., 10(2011)13291335. https://doi.org/10.4236/jmmce.2011.1014104

86. M. Singh, D.P. Mondal and S. Das, Abrasive wear response of aluminium alloysillimanite particle reinforced composite under low-stress condition, Mater. Sci. Eng. A, 419A(2006)59-68. https://doi.org/10.1016/j.msea.2005.11.056

87. D.P. Mondal and S. Das, High-stress abrasive wear behaviour of aluminium hard particle composites: Effects of experimental parameters, particle size and volume fraction, Tribo. Int., 39(2006)470-478. https://doi.org/10.1016/j.triboint.2005.03.003

88. C. García-Cordovilla, J. Narciso and E. Louis, Abrasive wear resistance of aluminium alloy/ceramic particulate composites, Wear, 192(1996)170-177. https://doi.org/10.1016/00431648(95)06801-5

89. B.K. Prasad, A.K. Jha, O.P. Modi, S. Das and A.H. Yegneswaran, Abrasive wear characteristics of a $\mathrm{Zn}-37.2 \mathrm{Al}-2.5 \mathrm{Cu}-0.2 \mathrm{Mg}$ alloy dispersed with silicon carbide particles, Mater. Trans. JIM, 36(1995)1048-1057.

90. B.K. Prasad, O.P. Modi and H.K. Khaira, High-stress abrasive wear behaviour of a zinc-based alloy and its composite compared with a cast iron under varying track radius and load conditions, Mater. Sci. Eng. A, 381A(2004)343-354. https://doi.org/10.1016/j.msea.2004.04.030

91. Y. Sahin and K. Ozdin, A model for the abrasive wear behaviour of aluminium based composites, Mater. Des., 29(2008)728-733. https://doi.org/10.1016/j.matdes.2007.02.013
92. S.A. Kassim, N.Y. Humberto and B.M.J. Daniel, Two-body abrasive wear of Al-SiC composites, Wear, 233-235(1999)444-454. https://doi.org/10.1016/S00431648(99)00185-4

93. C.T. Wu, S.L. Lee, M.H. Hsiegh and J.C. Lin, Effects of Mg content on microstructure and mechanical properties of Al-14.5Si4.5 $\mathrm{Cu}$ alloy, Metall. Mater. Trans. A, 41 A(2010)751-757. https://doi.org/10.1007/s11661-009-0133-6

94. K. Liu, X. Cao and X.G. Chen, Solid state transformation of iron-rich intermetallic phases in Al-Cu 206 cast alloys during solution heat treatment, Metall. Mater. Trans. A, 44A(2013)3494-3503. https://doi.org/10.1007/s11661-013-1726-7

95. S. Rathod, O.P. Modi, B.K. Prasad, A. Chrysanthou, D. Vallauri, V.P. Deshmukh and A.K. Shah, Cast in-situ Cu-TiC composites: synthesis by SHS route and characterization, Mater. Sci. Eng. A, 502A(2009)91-98. https://doi.org/10.1016/j.msea.2008.10.002

96. A.P. Mercer and I.M. Hutchings, The deterioration of bonded abrasive papers during the wear of metals, Wear, 132(1989)77-97. https://doi.org/10.1016/00431648(89)90204-4

97. B.K. Prasad, A.K. Patwardhan and A.H. Yegneswaran, Microstructure and property characterization of a modified zinc-based alloy and comparison with bearing alloys, J. Mater. Eng. Perf., 7(1998)130-135. https://doi.org/10.1361/10599499877034815 $\underline{1}$

98. B.K. Prasad, A.K. Patwardhan and A.H. Yegneswaran, Factors controlling the dry sliding wear behaviour of a leaded-tin bronze, Mater. Sci. Technol., 12(1996)427435. https://doi.org/10.1179/02670839679016588 $\underline{5}$

99. O.P. Modi, B.K. Prasad, A.H. Yegneswaran and M.L. Vaidya, Dry sliding wear behaviour of squeeze cast aluminium alloy-silicon carbide composites, Mater. Sci. Eng. A, 151A(1992)235-245. https://doi.org/10.1016/0921-5093(92)9 